\title{
Re-irradiation with 36 Gy (1.5 Gy Twice Daily) Plus Paclitaxel for Advanced Recurrent and Previously Irradiated SCCHN is Feasible
}

\author{
DIRK RADES ${ }^{1}$, TOBIAS BARTSCHT ${ }^{2}$, CHRISTIAN IDEL ${ }^{1,3}$ and SAMER G. HAKIM ${ }^{4}$ \\ Departments of ${ }^{1}$ Radiation Oncology, Hematology and ${ }^{2}$ Medical Oncology, Oto-Rhino-Laryngology and \\ ${ }^{3}$ Head and Neck Surgery and ${ }^{4}$ Oral and Maxillofacial Surgery, University of Lübeck, Lübeck, Germany
}

\begin{abstract}
Background/Aim: Many patients developing a loco-regional recurrence of squamous cell carcinoma of head and neck (SCCHN) have a poor prognosis. Often, recurrences are unresectable, and patients require a second course of radiotherapy or chemoradiation. We present an approach of chemoradiation including mainly 30 Gy of radiotherapy (1.5 Gy twice daily) plus concurrent paclitaxel. To further improve the prognoses of these patients, we increased the radiation dose from 30 to $36 \mathrm{~Gy}$. Patients and Methods: In four patients with recurrent and previously irradiated SCCHN (60-70 Gy) chemoradiation was carried out using 36 Gy (1.5 Gy twice daily) and concurrent paclitaxel (4-5 times $20-25 \mathrm{mg} / \mathrm{m}^{2}$ ). Results: One-year loco-regional control rates were $75 \%$ inside and $67 \%$ outside re-irradiated regions. One-year survival was $50 \%$, and median survival time 11 months. Toxicities were mild (grade 0-2). Conclusion: Re-irradiation with 36 Gy (1.5 Gy twice daily) plus paclitaxel appears feasible and may lead to promising outcomes. This study is preceding a phase I trial.
\end{abstract}

About half the patients who were treated for advanced nonmetastatic squamous cell carcinoma of the head and neck $(\mathrm{SCCHN})$ develop a loco-regional recurrence either at the primary tumor site and/or in regional lymph nodes (1-3). In case of such a recurrence, a complete resection is often not safely possible, and the patients are referred to radiotherapy, ideally combined with concurrent chemotherapy (4). However, many of these patients had already received 60-70 Gy of radiotherapy

This article is freely accessible online.

Correspondence to: Professor Dirk Rades, Department of Radiation Oncology, University of Lübeck, Ratzeburger Allee 160, 23538 Lübeck, Germany. Tel: +49 4515006661, Fax: +49 4515003324, e-mail: rades.dirk@gmx.net

Key Words: SCCHN, loco-regional recurrence, re-irradiation, chemoradiation, paclitaxel. (usually with 5 daily fractions of 2 Gy per week) as part of their primary treatment, either as a definitive or an adjuvant approach. For the treatment of a loco-regional recurrence, the second course of radiotherapy cannot be safely administered with 60-70 Gy again when taking into account the tolerance doses of the organs at risk in the head and neck region (5). This problem may be partly overcome with the addition of concurrent chemotherapy, which can be assumed to represent more than additional $10 \%$ of the radiotherapy dose regarding the effect of tumor cell kill (6). Cisplatin and carboplatin are the most commonly used agents for SCCHN. However, many patients, particularly in recurrent disease after chemoradiation, may not be able to receive platin-based chemotherapy again due to expected toxicity such as nausea, vomiting and renal failure (7). For these patients, taxanes may be an alternative option, since these agents have been proved effective as a monotherapy in patients with SCCHN (8-10). In addition to concurrent chemotherapy, twice-daily administration of radiotherapy with lower doses per fraction (e.g. of $1.5 \mathrm{~Gy}$ ) is a relatively novel approach to improve treatment outcome in such coditions. The risk of late radiation morbidity can be decreased with the use of lower doses per fraction (11). Normal tissues can recover from radiotherapy after 6 to 8 hours, whereas tumor cells generally do not recover. We followed this approach in a previous report of patients receiving mainly 30 Gy of radiotherapy with two daily fractions of 1.5 Gy supplemented by $20-25 \mathrm{mg} / \mathrm{m}^{2}$ of paclitaxel administered twice weekly (12). However, the question arose whether a better outcome could be achieved with a higher radiation dose than $30 \mathrm{~Gy}$. Therefore, we increased the total radiation dose to $36 \mathrm{~Gy}$ in the present series and investigated the feasibility and efficacy of this regimen.

\section{Patients and Methods}

Four patients with head-and-neck cancer, two women and two men, underwent this therapy regimen. These patients had developed an advanced loco-regional recurrence of SCCHN following surgery plus postoperative platin-based chemoradiation. Two patients had oropharynx cancer, one patient cancer of the oral cavity and one 
Table I. Outcomes of the patients, referenced from the first day of re-irradiation.

\begin{tabular}{lcccc}
\hline Patient & Paclitaxel dose & In-field recurrence & Out-field recurrence & Death \\
\hline Patient 1 & $4 \times 20 \mathrm{mg} / \mathrm{m}^{2}$ & No & Yes (after 9 months*) & Yes (after 13 months) \\
Patient 2 & $5 \times 20 \mathrm{mg} / \mathrm{m}^{2}$ & Yes (after 3 months**) & No & Yes (after 9 months) \\
Patient 3 & $4 \times 25 \mathrm{mg} / \mathrm{m}^{2}$ & No & No & No (alive after 64 months) \\
Patient 4 & $5 \times 25 \mathrm{mg} / \mathrm{m}^{2}$ & No & No & Yes (after 8 months) \\
\hline
\end{tabular}

*Recurrence in the head-and neck region outside re-irradiated areas; **recurrence inside re-irradiated areas.

patient larynx cancer. Initial tumor stages ranged from $\mathrm{T} 1 \mathrm{~N} 2 \mathrm{~b}$ to $\mathrm{T} 4$ $\mathrm{N} 2 \mathrm{~b}$. Initial treatment included surgery followed by radiotherapy (60-70 Gy with 5 daily fractions of 2.0 Gy per week) supplemented by concurrent platin-based chemotherapy.

The median interval between the end of initial radiotherapy and the start of re-irradiation for the loco-regional recurrence was 103 months (range $=14-225$ months). Loco-regional recurrence consisted of an isolated recurrence of the primary tumor in two patients, an isolated recurrence of cervical lymph nodes in one patient and a recurrence of both primary tumor and lymph nodes in one patient. Re-treatment consisted of chemoradiation with $36 \mathrm{~Gy}$ of radiotherapy (two daily fractions of 1.5 Gy with an interval between the fractions of at least 6 hours given on five consecutive days per week). Radiotherapy was performed as volumetric modulated arc therapy encompassing the recurrence plus margins of $2-3 \mathrm{~cm}$. It was supplemented by concurrent administration of paclitaxel (infusion over 1 hour) at doses of $20-25 \mathrm{mg} / \mathrm{m}^{2}$ twice per week. In total, the patients received $4 \times 20 \mathrm{mg} / \mathrm{m}^{2}, 5 \times 20 \mathrm{mg} / \mathrm{m}^{2}, 4 \times 25 \mathrm{mg} / \mathrm{m}^{2}$ and $5 \times 25$ $\mathrm{mg} / \mathrm{m}^{2}$ of paclitaxel, respectively (Table I). Premedication included 2 $\mathrm{mg}$ of clemastine, $1 \mathrm{mg}$ of granisetron and $8 \mathrm{mg}$ of dexamethasone, all given intravenously.

Investigated treatment outcomes included loco-regional control defined as freedom from another loco-regional recurrence in the head-and-neck region (inside or outside re-irradiated ares), metastases-free survival and survival, calculated from the first day of re-irradiation. These analyses were performed with the KaplanMeier method. In addition, acute toxicity was assessed using the Common Terminology Criteria of Adverse Events (CTCAE) version 4.0 (13).

\section{Results}

Following the chemoradiation with 36 Gy plus paclitaxel for recurrent SCCHN, the 1-year rates of overall loco-regional control, loco-regional control outside re-irradiated areas and loco-regional control inside re-irradiated areas were $38 \%$ (Figure 1), 67\% (Figure 2) and 75\% (Figure 3), respectively. Distant metastases were not observed during the follow-up period (median=11 months in all patients).

The 1-year rate of survival was $50 \%$ (Figure 4), and the median survival time was 11 months. The individual outcomes of the four patients are given in Table I. The treatment was well tolerated by all patients. Acute toxicities were grade 2 or less according to CTCAE version 4.0 (Table II).

\section{Discussion}

In patients developing a loco-regional recurrence of SCCHN, a complete resection is often not safely possible and the patients receive chemoradiation or radiotherapy alone, either as definitive treatment or following debulking surgery (4, 14). The recommended curative radiotherapy dose amounts to $60 \mathrm{~Gy}$ or higher. However, if the patients had already received chemoradiation or radiotherapy as part of their primary treatment, a second course of radiotherapy with at least $60 \mathrm{~Gy}$ is not possible considering the tolerance doses of the surrounding normal tissues. The risk of late radiation damage to these structures can be significantly decreased using a dose per fraction of less than 1.8-2.0 Gy such as $1.5 \mathrm{~Gy}$ (8). If doses per fraction of $1.5 \mathrm{~Gy}$ are administered twice daily with an interval of 6-8 hours, irradiated normal tissues are able to recover between the two fractions in contrast to the tumor cells. To further augment the efficacy of re-irradiation, radiotherapy may be supplemented by concurrent chemotherapy (6). Cisplatin, the most common agent, may lead to significant side effects and cannot be used in many patients with recurrent SCCHN (7). Beside other systemic treatments, paclitaxel may be an alternative option for these patients, which has been reported to be effective and associated with favorable toxicity profiles (8-10). For example, in a prospective study of 35 patients with locally advanced SCCHN, 70.2-72 Gy of radiotherapy plus three courses of paclitaxel resulted in a median survival of 56.5 months, and most toxicities were grade 2 or less (9). Furthermore, a randomized phase II trial compared $65 \mathrm{~Gy}$ of radiotherapy plus concurrent gemcitabine $\left(100 \mathrm{mg} / \mathrm{m}^{2}\right.$ weekly) or paclitaxel $\left(20 \mathrm{mg} / \mathrm{m}^{2}\right.$ weekly) in a total of 216 patients with locally advanced SCCHN (10). At 2 years, survival and freedom from progression rates were better in the paclitaxel group than in the gemcitabine group $(67 \%$ versus 56\%, respectively, and $64 \%$ versus $54 \%$, respectively). Moreover, paclitaxel was associated with significantly less grade 3 mucositis (24\% versus $36 \%$, $p=0.04$ ) and grade 3 radiation dermatitis (13\% versus $24 \%$, $p=0.049$ ). These promising results led to our previous report investigating chemoradiation with paclitaxel in patients with 


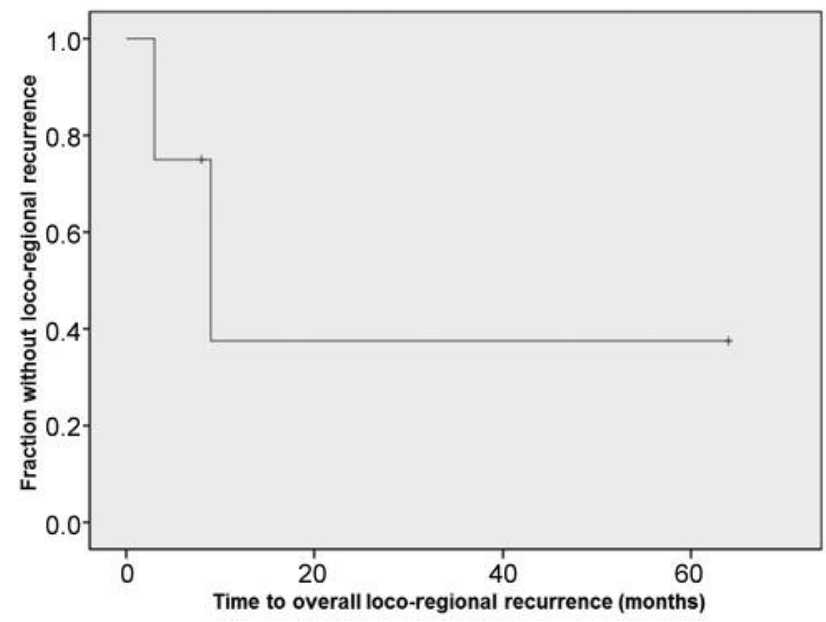

Figure 1. Kaplan-Meier curve for overall loco-regional control (control inside and outside re-irradiated areas in the head-and neck region).

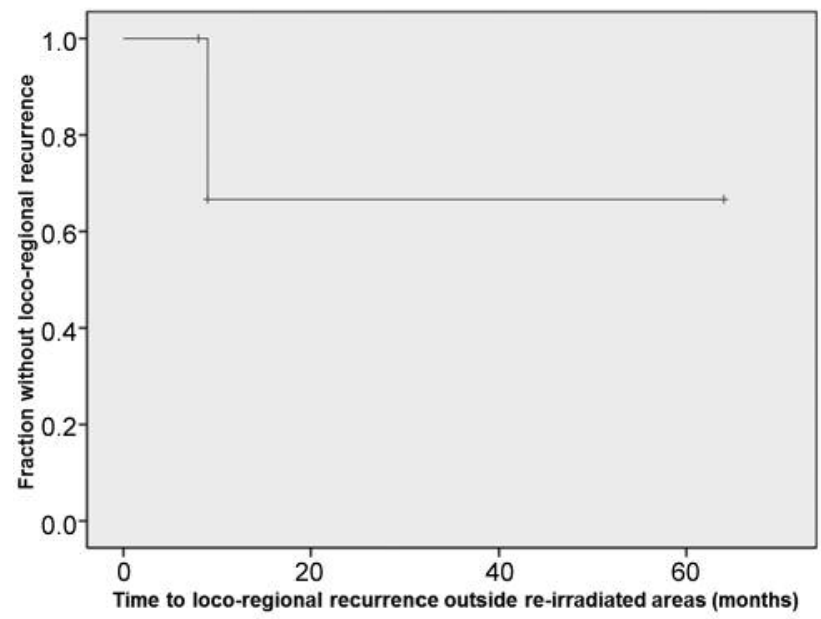

Figure 2. Kaplan-Meier curve for loco-regional control outside reirradiated areas.

a loco-regional recurrence of SCCHN (12). The patients mainly received $30 \mathrm{~Gy}$ of radiotherapy with two daily fractions of $1.5 \mathrm{~Gy}$ plus concurrent paclitaxel $\left(20-25 \mathrm{mg} / \mathrm{m}^{2}\right.$ twice per week). This regimen was very well tolerated. Toxicity was mostly limited to grade 1 , grade 3 toxicity was not observed. Moreover, the 1-year survival rate of $75 \%$ was more favorable than in most other recent studies using chemoradiation or external beam radiotherapy alone including modern high-precision techniques such as tomotherapy, CyberKnife ${ }^{\circledR}$, protons and charged particles for an advanced loco-regional recurrence of SCCHN. The 1-year

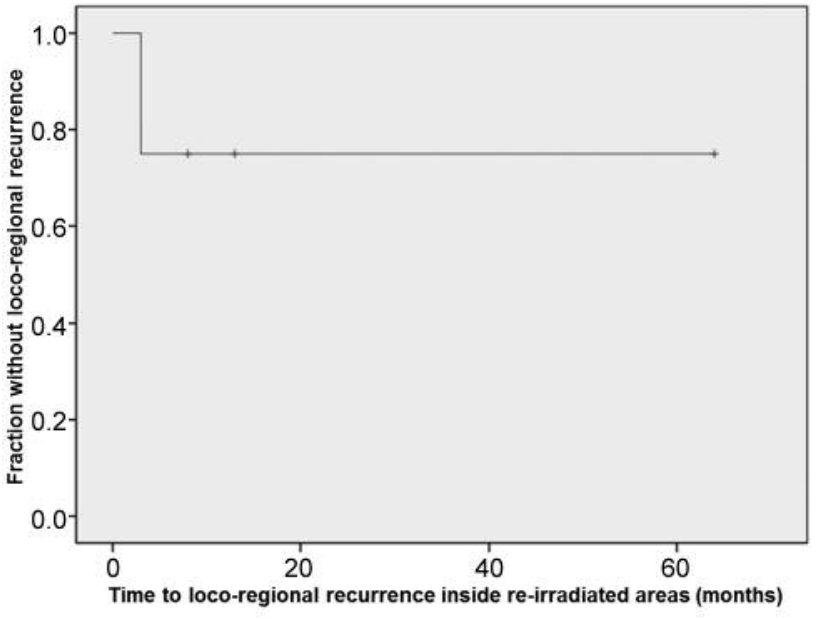

Figure 3. Kaplan-Meier curve for loco-regional control inside reirradiated areas.

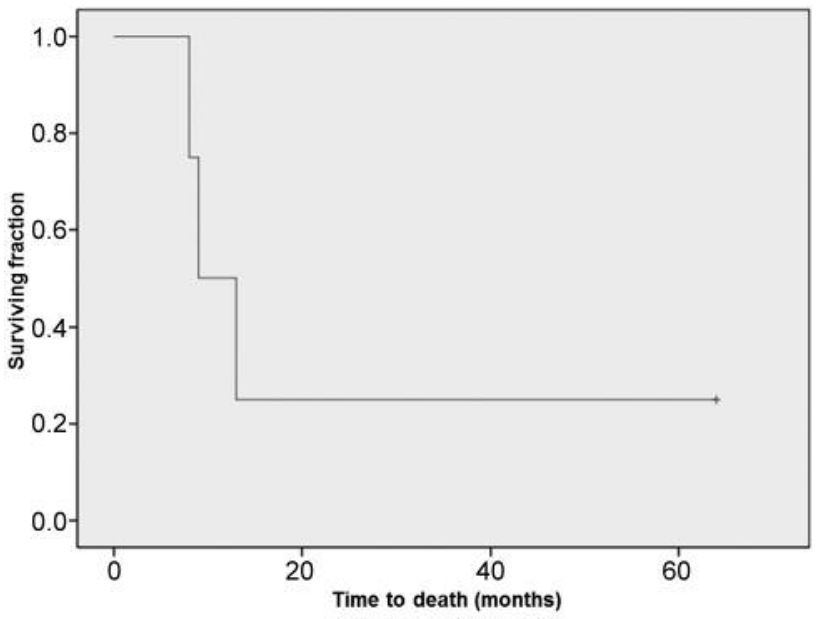

Figure 4. Kaplan-Meier curve for survival.

survival rates in most of the other studies ranged from $33 \%$ to $62.5 \%$ (15-19). In one study using conformal radiotherapy, intensity-modulated radiotherapy or tomotherapy, the survival at 1 year was $77 \%$ (20).

The results of our previous study (12) and the question whether the results can be further improved by increasing the radiation dose led to the present study. The radiation dose was increased to 36 Gy supplemented by 4-5 administrations of $20-25 \mathrm{mg} / \mathrm{m}^{2}$ of paclitaxel. Again, the outcomes were quite promising taking into account that the recurrent tumors were more advanced than in our previous study. The 1-year 
Table II. Toxicity according to CTCAE version 4.0.

\begin{tabular}{|c|c|}
\hline & No. of patients \\
\hline \multicolumn{2}{|c|}{ Oral mucositis } \\
\hline None & 0 \\
\hline Grade 1 & 1 \\
\hline Grade 2 & 3 \\
\hline \multicolumn{2}{|c|}{ Radiation dermatitis } \\
\hline None & 0 \\
\hline Grade 1 & 4 \\
\hline Grade 2 & 0 \\
\hline \multicolumn{2}{|l|}{ Xerostomia } \\
\hline None & 3 \\
\hline Grade 1 & 2 \\
\hline Grade 2 & 0 \\
\hline \multicolumn{2}{|c|}{ Lymph edema } \\
\hline None & 3 \\
\hline Grade 1 & 1 \\
\hline Grade 2 & 0 \\
\hline \multicolumn{2}{|l|}{ Anemia } \\
\hline None & 2 \\
\hline Grade 1 & 0 \\
\hline Grade 2 & 2 \\
\hline \multicolumn{2}{|l|}{ Leucopenia } \\
\hline None & 4 \\
\hline Grade 1 & 0 \\
\hline Grade 2 & 0 \\
\hline \multicolumn{2}{|c|}{ Thrombopenia } \\
\hline None & 4 \\
\hline Grade 1 & 0 \\
\hline Grade 2 & 0 \\
\hline \multicolumn{2}{|c|}{ Nausea/vomiting } \\
\hline none & 4 \\
\hline Grade 1 & 0 \\
\hline Grade 2 & 0 \\
\hline \multicolumn{2}{|c|}{ Renal toxicity } \\
\hline None & 4 \\
\hline Grade 1 & 0 \\
\hline Grade 2 & 0 \\
\hline
\end{tabular}

loco-regional control rate inside the re-irradiated areas of $75 \%$ was at the top of the range of $44-80 \%$ found in other studies (15-20). And the 1-year survival rate of $50 \%$ was well in the range of $33 \%$ to $77 \%$ reported in the other studies. The chemoradiation regimen used in the present study was well tolerated; grade 3 toxicities were not observed. In other studies, grade 3 or greater toxicities were reported in up to $36 \%$ of patients and treatment-related deaths in up to $12 \%$ of patients (15-20).

In conclusion, re-irradiation with 36 Gy $(1.5$ Gy twice daily) plus $20-25 \mathrm{mg} / \mathrm{m}^{2}$ of paclitaxel administered twice weekly appears feasible and may lead to promising locoregional control and survival rates. This study will drive forth to a phase I trial aiming to identify the appropriate radiation dose when combined with paclitaxel in patients with recurrent and previously irradiated SCCHN.

\section{Conflicts of Interest}

On behalf of all Authors, the corresponding Author states that there is no conflict of interest related to this study.

\section{References}

1 Bernier J, Domenge C, Ozsahin M, Matuszewska K, Lefèbvre JL, Greiner RH, Giralt J, Maingon P, Rolland F, Bolla M, Cognetti F, Bourhis J, Kirkpatrick A and van Glabbeke M: European Organization for Research and Treatment of Cancer Trial 22931: Postoperative irradiation with or without concomitant chemotherapy for locally advanced head and neck cancer. N Engl J Med 350: 1945-1952, 2004.

2 Cooper JS, Pajak TF, Forastiere AA, Jacobs J, Campbell BH, Saxman SB, Kish JA, Kim HE, Cmelak AJ, Rotman M, Machtay M, Ensley JF, Chao KS, Schultz CJ, Lee $\mathrm{N}$ and Fu KK: Radiation Therapy Oncology Group 9501/Intergroup: Postoperative concurrent radiotherapy and chemotherapy for high-risk squamous-cell carcinoma of the head and neck. N Engl J Med 350: 1937-1944, 2004.

3 Lefebvre JL, Rolland F, Tesselaar M, Bardet E, Leemans CR, Geoffrois L, Hupperets P, Barzan L, de Raucourt D, Chevalier D, Licitra L, Lunghi F, Stupp R, Lacombe D, Bogaerts J, Horiot JC, Bernier $\mathrm{J}$ and Vermorken JB; EORTC Head and Neck Cancer Cooperative Group; EORTC Radiation Oncology Group: Phase 3 randomized trial on larynx preservation comparing sequential $v s$. alternating chemotherapy and radiotherapy. J Natl Cancer Inst 101: 142-152, 2009.

4 Kostrzewa JP, Lancaster WP, Iseli TA, Desmond RA, Carroll WR and Rosenthal EL: Outcomes of salvage surgery with free flap reconstruction for recurrent oral and oropharyngeal cancer. Laryngoscope 120: 267-272, 2010.

5 Marks LB, Yorke ED, Jackson A, Ten Haken RK, Constine LS, Eisbruch A, Bentzen SM, Nam J and Deasy JO: Use of normal tissue complication probability models in the clinic. Int J Radiat Oncol Biol Phys 76(3 Suppl): S10-19, 2010.

6 Budach V, Stuschke M, Budach W, Baumann M, Geismar D, Grabenbauer G, Lammert I, Jahnke K, Stueben G, Herrmann T, Bamberg M, Wust P, Hinkelbein W and Wernecke KD: Hyperfractionated accelerated chemoradiation with concurrent fluorouracil-mitomycin is more effective than dose-escalated hyperfractionated accelerated radiation therapy alone in locally advanced head and neck cancer: final results of the radiotherapy cooperative clinical trials group of the German Cancer Society 95-06 Prospective Randomized Trial. J Clin Oncol 23: 11251135, 2005.

7 De Castro G Jr, Snitcovsky IM, Gebrim EM, Leitão GM, Nadalin W, Ferraz AR and Federico MH: High-dose cisplatin concurrent to conventionally delivered radiotherapy is associated with unacceptable toxicity in unresectable, non-metastatic stage IV head and neck squamous cell carcinoma. Eur Arch Otorhinolaryngol 264: 1475-1482, 2007.

8 Lövey J, Koronczay K, Remenár E, Csuka O and Németh G: Radiotherapy and concurrent low-dose paclitaxel in locally advanced head and neck cancer. Radiother Oncol 68: 171-174, 2003.

9 Citrin D, Mansueti J, Likhacheva A, Sciuto L, Albert PS, Rudy SF, Cooley-Zgela T, Cotrim A, Solomon B, Colevas AD, Russo A, Morris JC, Herscher L, Smith S and Van Waes C: Long-term 
outcomes and toxicity of concurrent paclitaxel and radiotherapy for locally advanced head-and-neck cancer. Int J Radiat Oncol Biol Phys 74: 1040-1046, 2009.

10 Halim AA, Wahba HA, El-Hadaad HA and Abo-Elyazeed A: Concomitant chemoradiotherapy using low-dose weekly gemcitabine versus low-dose weekly paclitaxel in locally advanced head and neck squamous cell carcinoma: a phase III study. Med Oncol 29: 279-284, 2012.

11 Joiner MC and Van der Kogel AJ: The linear-quadratic approach to fractionation and calculation of isoeffect relationships. In: Basic clinical radiobiology. Steel GG (eds.). New York, Oxford University Press, pp. 106-112, 1997.

12 Rades D, Seidl D, Wollenberg B, Schild SE and Hakim SG: Radiochemotherapy with paclitaxel for recurrent previously irradiated squamous cell carcinoma of the head and neck. Anticancer Res 36: 5463-5468, 2016.

13 National Institutes of Health/National Cancer Institute: Common Terminology Criteria for Adverse Events (CTCAE) version 4.0. National Institutes of Health/National Cancer Institute, 2009.

14 Seidl D, Schild SE, Wollenberg B, Hakim SG and Rades D: Prognostic factors in patients irradiated for recurrent head-andneck cancer. Anticancer Res 36: 6547-6550, 2016.

15 Cvek J, Knybel L, Skacelikova E, Stransky J, Matousek P, Zelenik K, Res O, Otahal B, Molenda L and Feltl D: Hyperfractionated stereotactic reirradiation for recurrent head and neck cancer. Strahlenther Onkol 192: 40-46, 2016.

16 Dornoff N, Weiß C, Rödel F, Wagenblast J, Ghanaati S, Atefeh $\mathrm{N}$, Rödel C and Balermpas P: Re-irradiation with cetuximab or cisplatin-based chemotherapy for recurrent squamous cell carcinoma of the head and neck. Strahlenther Onkol 191: 656$664,2015$.
17 Hayashi Y, Nakamura T, Mitsudo K, Kimura K, Yamaguchi H, Ono T, Azami Y, Takayama K, Hirose K, Yabuuchi T, Suzuki M, Hatayama Y, Kikuchi Y, Wada H, Fuwa N, Hareyama M and Tohnai I: Re-irradiation using proton beam therapy combined with weekly intra-arterial chemotherapy for recurrent oral cancer. Asia Pac J Clin Oncol 13: e394-e401, 2016.

18 Jeong S, Yoo EJ, Kim JY, Han CW, Kim KJ and Kay CS: Reirradiation of unresectable recurrent head and neck cancer: using Helical Tomotherapy as image-guided intensity-modulated radiotherapy. Radiat Oncol J 31: 206-215, 2013.

19 Al-Wassia R, Vakilian S, Holly C, Sultanem K and Shenouda G: A retrospective study of head and neck re-irradiation for patients with recurrent or second primary head and neck cancer: the McGill University experience. J Otolaryngol Head Neck Surg 44: 31, 2015.

20 Yamazaki H, Demizu Y, Okimoto T, Ogita M, Himei K, Nakamura S, Suzuki G, Yoshida K, Kotsuma T and Yoshioka Y: Comparison of re-irradiation outcomes for charged particle radiotherapy and robotic stereotactic radiotherapy using cyberknife for recurrent head and neck cancers: A multiinstitutional matched-cohort analysis. Anticancer Res 36(10): 5507-5514, 2016.
Received October 20, 2017

Revised November 1, 2017

Accepted November 2, 2017 